\section{What is already known on this topic}

Lung cancer mortality among men is higher in central and eastern Europe than in the 15 original (western) states of the European Union

For each sex, lung cancer rates are distinctly higher in Hungary than elsewhere

\section{What this study adds}

Lung cancer mortality is now falling in middle aged men in all new EU states in central and eastern Europe but is still rising among women in most EU countries

found among men (Sweden, Denmark, and the Netherlands; figure).

\section{Comment}

Falling death rates due to lung cancer in the male populations of central and eastern Europe since at least the mid-1990s imply that trends in tobacco exposure in young men have been favourable since at least the early 1980s. The reasons for this need to be explored further and may include changes in prevalence, consumption, or modifications made to cigarettes since this time. ${ }^{4}$

Lung cancer epidemics among women show no consistent pattern that follows those in men, either in timing or in relative magnitude. This implies that the model advanced by Lopez et al in $1992^{5}$ is too simple in this respect. The very high mortality figures for Hungary merit further investigation.

When attention is focused not on the absolute rates, in men, of diseases caused by smoking but rather on the direction and magnitude of change in younger adults, new EU member states from central and eastern Europe are no longer at the bottom of the class. The favourable trends for men would also hold promise for future trends in women if these could be predicted from trends in men. However, these data show that this is unlikely to be the case, emphasising the continuing need for strong antismoking programmes for both sexes.

Contributors: JD conducted the analysis and cowrote the paper. MM conducted the analysis, cowrote, and edited the paper. $\mathrm{AMcN}$ and JP took part in editing the paper. WZ planned, conducted the analysis, wrote, and edited the paper. WZ is the guarantor.

Funding: This work was supported by the Closing the Gap Project, funded by the European Union Directorate for Health and Consumer Protection, Action 2003121.

Competing interests: None declared.

1 Peto R, Lopez AD, Boreham J, Thun M, Heath JrC. Mortality from smoking in developed countries 1950-2000. Oxford: Oxford University Press; 1994 Peto R, Darby S, Deo H, Silcocks P, Whitley E, Doll R. Smoking, smoking cessation, and lung cancer in the UK since 1950: combination of national statistics with two case-control studies. BMJ 2000;321:323-9.

3 Brennan P, Bray I. Recent trends and future directions for lung cancer mortality in Europe. Br J Cancer 2002;87:43-8.

4 Zatonski W. Tobacco smoking in central European countries: Poland. In: Boyle P, Gray N, Henningfield J, Seffrin J, Zatonski W, eds. Tobacco and public health: science and policy. Oxford: Oxford: University Press, 2004:235-52.

5 Lopez AD, Collishaw NE, Piha T. A descriptive model of the cigarette epidemic in developed countries. Tob Control 1994:3:243-7.

\title{
Commentary: Making the transition to action
}

\author{
Eva Kralikova, Erzsebet Podmaniczky, Hanna Stypułkowska-Misiurewicz, Elena Kavcova,
} Aurelijus Veryga, Tanith Muller

The news on smoking from the European Union's eastern frontiers is better than expected, with no evidence of a future gulf in lung cancer mortality between old and new member states. ${ }^{1}$ However, the special challenges faced by the eastern transitional economies-such as aggressive tobacco marketing, rapid liberalisation of the tobacco trade, and the political influence of the leading tobacco companies ${ }^{2}-$ remain. And a closer look at the study by Didkowska et $\mathrm{al}^{1}$ shows just how much work is still needed throughout the EU to reduce deaths from lung cancer and from other tobacco related disease.

The tobacco epidemic cannot be allowed to proceed without active intervention. Tobacco remains Europe's single biggest cause of preventable death. Lung cancer still accounts for more than a quarter of the EU's male cancer deaths and a rising number of deaths in women, ${ }^{3}$ and tobacco related diseases cause 650000 unnecessary deaths every year in the EU. ${ }^{4}$ Tobacco control has been identified as a priority in central and eastern Europe, ${ }^{3}$ but its importance cannot be restricted to these countries.

Throughout Europe, tobacco companies have proved adept at expanding and maintaining their mar- kets, especially among women. Marketing a life shortening addiction as liberation has proved a highly effective strategy in countries as diverse as Hungary, France, and Spain. There is no sign that the women's market has reached saturation point in most countries, and a far greater number of women will die if doctors and governments alike do not act. Despite having declined, tobacco related deaths in males remain frighteningly high.

The unpalatable truth is that both old and new EU states have made very limited progress in reducing tobacco use and its associated diseases in the past 50 years. Despite the evidence that half of all long term smokers will die prematurely as a result of smoking, ${ }^{5}$ both doctors and governments have found it hard to kick their addictions to tobacco. From those doctors whose own smoking stops them advising their patients to quit, to governments in thrall to tobacco companies' wealth, there can be no excuse for inaction.

The medical profession has a key role to play. Treatment for tobacco dependence is a cost effective intervention that will improve the health of patients who smoke; and doctors can advise governments as well as patients. Moreover, because
Institute of Hygiene and Epidemiology, Charles University,

Prague, Czech

Republic

Eva Kralikova

lecturer

Hungarian Medical Chamber, Budapest, Hungary

Erzsebet

Podmaniczk

president,

International

Relations Committee

Polish Chamber of

Physicians and

Dentists, Warsaw,

Poland

Hanna

Stypułkowska-Misiurewicz

international

relations officer

Department of

Tuberculosis and Respiratory

Diseases, Martin

Faculty Hospital,

Martin, Slovak

Republic

Elena Kavcova

lecturer

continued over 
Department of Preventive

Medicine, Kaunas

University, Kaunas,

Lithuania

Aurelijus Veryga

lecturer

Tobacco Control

Resource Centre

BMA, Edinburgh

EH2 1LL

Tanith Muller

director

Correspondence to:

T Muller

tmuller@bma.org.uk the tobacco industry operates in similar ways throughout the world, much can be achieved through sharing of information across national boundaries. All EU governments are expected to have ratified the WHO Framework Convention on Tobacco Control by the end of 2005. The world's first public health treaty commits governments to take action to reduce the disease, disability, and death caused by tobacco. The evidence based policies that it containssuch as increases in tobacco tax, advertising bans, smoke-free public places, and hard hitting picture warnings-have been proved to work. It's time for Europe's doctors to treat tobacco dependence in their patients. But it's also time to move out of the consulting room and demand that our governments take effective action too.

Competing interests: None declared.

1 Didkowska J, Manczuk M, McNeill A., Powles J, Zatonski W. Lung cancer mortality at ages 35-54 in the European Union: ecological study of evolving tobacco epidemics. $B M J$ 2005:331:189-91.

2 Gilmore A, McKee M. Tobacco and transition: an overview of industry investments, impact and influence in the former Soviet Union. Tob Control investments, impar

Boyle P, Ferlay J. Cancer incidence and mortality in Europe, 2004. Ann Oncol 2005; 16:481-8.

4 ASPECT Consortium. Tobacco or health in the European Union-past, present and future. Luxembourg: Office for Official Publications of the European Communities, 2004.

5 Doll R, Peto R, Boreham J, Sutherland S. Mortality in relation to smoking: 50 years' observation on male British doctors. BMJ 2004;328:1-10.

\section{Comparison of amount of biomedical research originating from the European Union and the United States}

Elpidoforos S Soteriades, Matthew E Falagas

Department of Environmental Health, Harvard School of Public

Health, Boston, MA

Elpidoforos S

Soteriades

research fellow

Alfa Institute of Biomedical Sciences (AIBS), 9 Neapoleos Street, 15123 Marousi, Athens Greece Matthew E Falagas director

Correspondence to: M E Falagas, m.falagas@aibs.gr

BMJ 2005;331:192-5

\section{Abstract}

Objective To examine and compare the research productivity of the European Union, the four "candidate" countries (those currently waiting to join the EU), and the United States in several fields of biomedical sciences.

Design A retrospective observational

study-bibliometric analysis.

Data sources Manuscripts published by authors from each country separately and from each group of countries for the period 1994 to 2004 and included in the Essential Science Indicators database of the Institute of Scientific Information.

Main outcome measures Number of published articles and number of citations, adjusted for gross domestic product and population size.

Results 1485749 articles were published by authors from the EU compared with 1356805 from the US. The research productivity of the first 15 countries to join the EU, adjusted for population, was lower $(76 \%)$ than that of the US-and even lower (66\%) when the 10 newest EU countries were included in the analysis. Conclusion The newest EU members and the EU candidate countries need further help and resources to increase their productivity, thereby improving the productivity of the EU as a whole.

The European Union and the United States are the leading powers in biomedical research and publications, although the US is ahead of the EU in most scientific disciplines. ${ }^{12}$ The EU has been gradually closing this gap, but the union's future expansion might widen the gap again in favour of the US. ${ }^{3}{ }^{4}$ We examined the biomedical research output of the EU's member countries and of four candidate countries for the EU, to compare the geographical distribution of output across Europe with the output in the US.

\section{Methods}

Our study covered the period 1994 to 2004 . We examined data for the US plus three groups of European

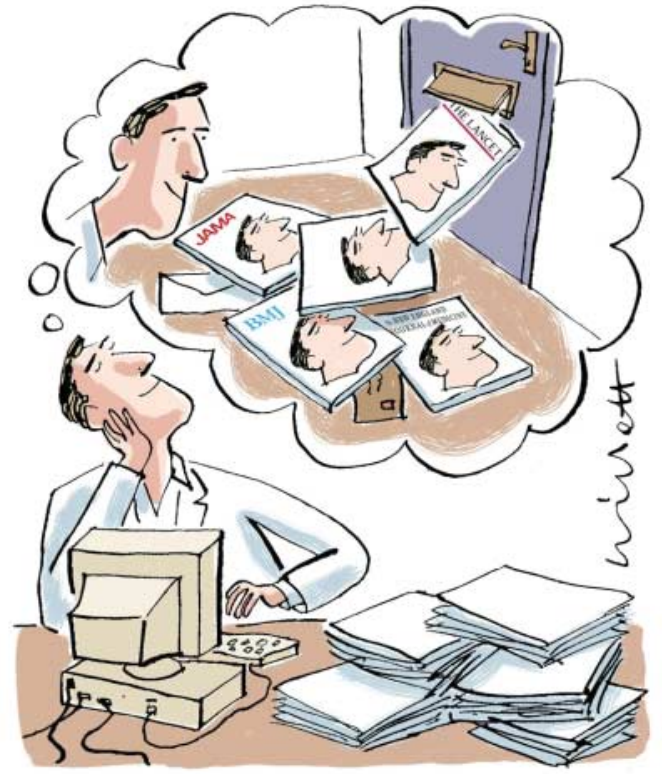

countries: (a) the first 15 states joining the EU (including three-Austria, Finland, Sweden-that did not join until January 1995); (b) the 10 countries that joined the EU in May 2004; and (c) the four "candidate" countries waiting to join (Bulgaria, Croatia, Romania, Turkey). We estimated the amount of research produced by each country separately and by each group, using the information included in the Essential Science Indicators database of the Institute for Scientific Information. A paper was attributed to any country (or countries) if an address for that country was given by one or more authors; therefore an article could be attributed to more than one country.

We focused our search on nine scientific fields: biology and biochemistry; clinical medicine; immunology; microbiology; molecular biology and genetics; multidisciplinary; neuroscience and behaviour; psychiatry and psychology; and pharmacology and toxicology. 